\title{
NOVEL APPROACH TO MANAGEMENT OF SECONDARY BRONCHIOLITIS OBLITERANS ORGANIZING PNEUMONIA FOLLOWING INFLUENZA A
}

Dushantha Madegedara *1凶, Ishelda Nawarathne 1, Lihini Basnayake 2, S. A.

Luckmy ${ }^{1}$ iD , B Imbulpitiya ${ }^{2}$

${ }^{1}$ Respiratory unit 2 National Hospital Kandy Sri Lanka, India

2 Medical ICU National Hospital Kandy Sri Lanka, India

DOI: https://doi.org/10.29121/granthaalayah.v8.i10.2020.2028

Article Type: Research Article

Article Citation: Dushantha Madegedara, Ishelda Nawarathne, Lihini Basnayake, S. A. Luckmy, and B Imbulpitiya. (2020). NOVEL APPROACH TO MANAGEMENT OF SECONDARY BRONCHIOLITIS OBLITERANS ORGANIZING PNEUMONIA FOLLOWING INFLUENZA A. International Journal of Research -GRANTHAALAYAH, 8(10), 292-297.

https://doi.org/10.29121/granthaa layah.v8.i10.2020.2028

Received Date: 14 October 2020

Accepted Date: 31 October 2020

Keywords:

Bronchiolitis Obliterans Organizing Pneumonia

Influenza A

Corticosteroid

Cyclophosphamide Treatment

\section{ABSTRACT}

A 50-year old man presented with a short history of fever, pleuritic type chest pain followed by progressively worsening dyspnea and hypoxemic respiratory failure. Influenza A virus antigen was identified from a throat swab. Mechanical ventilation and oseltamivir therapy were commenced, but was associated with an unfavorable response. Highresolution computed tomography (HRCT) of chest revealed features of Bronchiolitis Obliterans Organizing Pneumonia (BOOP). Here we report the 1st case of steroid resistant BOOP secondary to influenza A infection which subsequently responded well to Cyclophosphamide therapy.

\section{INTRODUCTION}

Bronchiolitis Obliterans Organizing Pneumonia (BOOP) is a rare inflammatory lung disease involving the distal and respiratory bronchiole, alveolar ducts and alveoli. BOOP can results from various causes, such as toxins, radiations, autoimmune disorders, medications, solid organ or bone marrow transplantation, certain bacteria and virus infections [1], [2]. The occurrence of BOOP following influenza A infection has rarely been described in the literature. Patient with confirmed influenza A and patients with high risk of developing it should be treated with Oseltemivir to prevent the sub-acute development of organizing pneumonia. Majority of patients with influenza A show a good response to antiviral treatment but some of them fail to show adequate response. In such cases, BOOP

(C) 2020 The Author(s). This is an open access article distributed under the terms of the Creative Commons Attribution License, which permits unrestricted use, distribution, and reproduction in any medium, provided the original author and source are credited. 
should be considered as a differential diagnosis especially when pneumonia does not respond to antiviral treatment. Usually B00P shows a dramatic response to corticosteroids [3], [4]. However, in some patients, who respond less well to steroids, other immunosuppressive agents are warranted [5]. Here we report the $1^{\text {st }}$ Sri Lankan patient with B00P secondary to influenza A infection which neither responded to antiviral nor to steroid therapy, but showed a remarkable response to pulses of cyclophosphamide therapy.

\section{CASE SUMMARY}

A 50- year- old previously healthy gentleman presented to Respiratory unit 2, National Hospital Kandy, Sri Lanka with a history of high-grade intermittent fever and dry cough for ten days duration. He also had bilateral pleuritic chest pain, malaise, arthralgia and myalgia. On seventh day of illness he developed breathlessness which progressed to MMRC grade III over the next two days. He was a nonsmoker and there were no history of exposure to chemicals, farm animals, or dust. Furthermore he denied of overseas travel and social misbehavior.

On examination, he was dyspnoeic with a respiratory rate of 28 cycles/min and febrile (temperature $38.5{ }^{\circ} \mathrm{C}$ ). His pulse rate was $94 / \mathrm{bpm}$ with normal blood lower pressure. The most striking feature of respiratory system examination was extensive coarse crepitations in bilateral zones extending to mid zones. Other systems examination was clinically unremarkable with no signs of secondary diseases including connective tissue disorders. Arterial blood gas analysis performed while breathing room air revealed $\mathrm{PaO}_{2}-62 \mathrm{mmHg} ; \mathrm{PaCO}_{2}-33 \mathrm{mmHg}$, $\mathrm{PH}-7.45$, arterial bicarbonate $-31 \mathrm{mmHg}$ and $\mathrm{SpO}_{2}-85 \%$. Further investigations on admission were as follow.

WBC $3.03 \times 10^{9} / \mathrm{l}$ (Lymphocyte $64 \%$ ), Hb $14.2 \mathrm{~g} / \mathrm{dL}$, platelets $143 \times 10^{9} / \mathrm{l}$, ESR $72 \mathrm{~mm} / 1^{\text {st }}$ hour. CRP $45 \mathrm{mg} / \mathrm{l}$, Na $140 \mathrm{mmol} / \mathrm{l}, \mathrm{K}^{+} 3.4 \mathrm{mmol} / \mathrm{l}, \mathrm{BU} 4.2 \mu \mathrm{mol} / \mathrm{l}$, S. Creatinine $102 \mu \mathrm{mol} / \mathrm{l}$, AST 51u/L, ALT 40u/L, and chest radiography revealed bilateral ground glass opacities with consolidations. (Figure 01) The throat swab antigen became positive for influenza A.

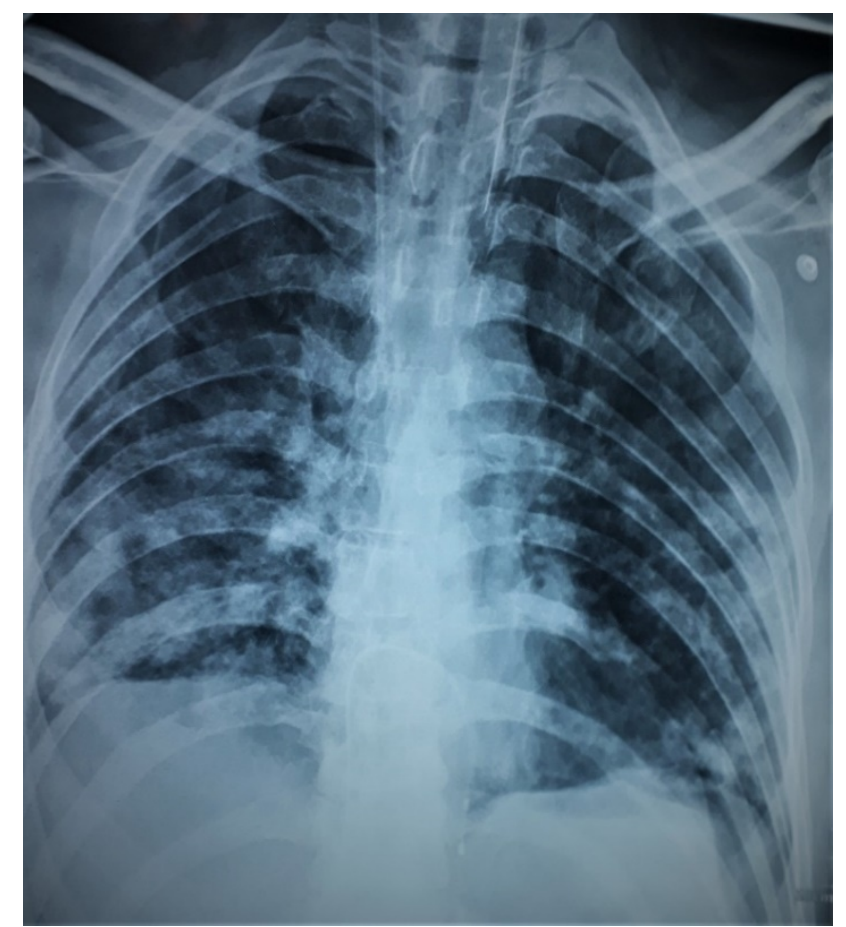

Figure 1: Chest radiography showing bilateral patchy consolidations

He received high flow oxygen via a face mask and Oseltamivir 75mg 12 hourly for 5 days. However, his condition deteriorated with worsening of hypoxia, requiring ICU care with mechanical ventilation. Furthermore, he developed a $2^{\text {nd }}$ degree heart block which required temporary pace maker insertion. Repeat hematological assessment showed high WBC count of $14 \times 10^{9} / \mathrm{l}$ with neutrophil 73\%, CRP of $198 \mathrm{mg} / \mathrm{l}$. Furthermore, retroviral studies, ANA, Rheumatoid factors were negative. He was treated with broad spectrum intravenous antibiotics as advised by clinical microbiologist after taking appropriate samples for cultures. Despite antimicrobials and supportive 
treatment, his respiratory parameters deteriorated further requiring escalation of ventilatory support. The chest radiography also deteriorated with appearance of new infiltrations. (Figure 02) The 2D Echocardiography and CT pulmonary angiogram were normal.

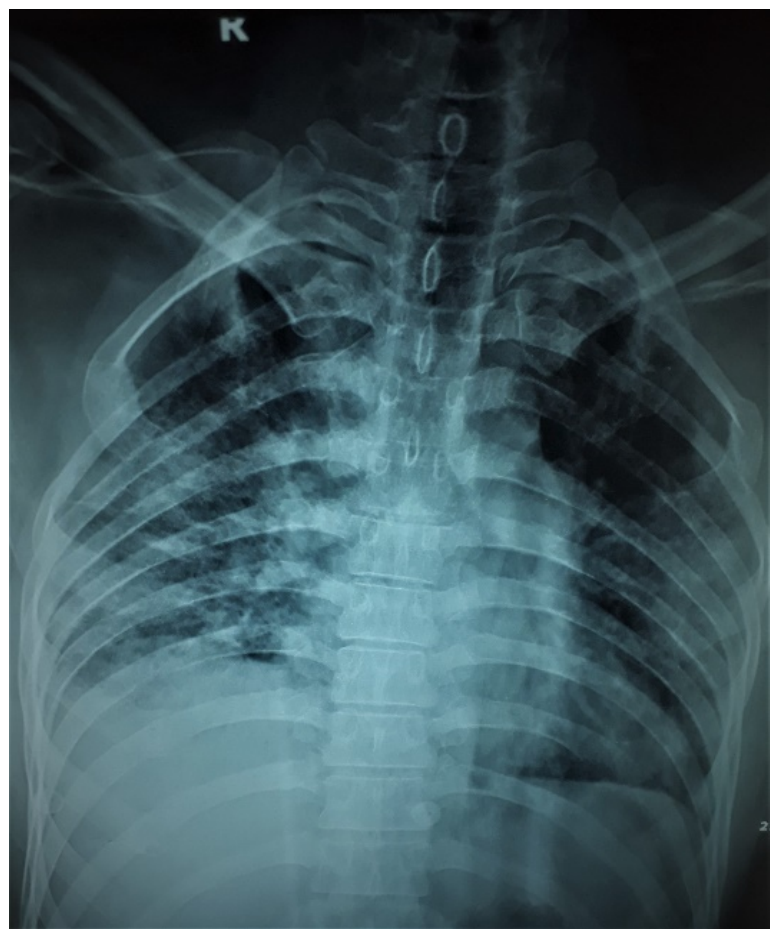

Figure 2: Chest radiography showing bilateral new infiltrates

A high-resolution CT (HRCT) chest revealed areas of consolidation, patchy ground glass infiltrates, nodules and mosaic attenuation. (Figure 03)

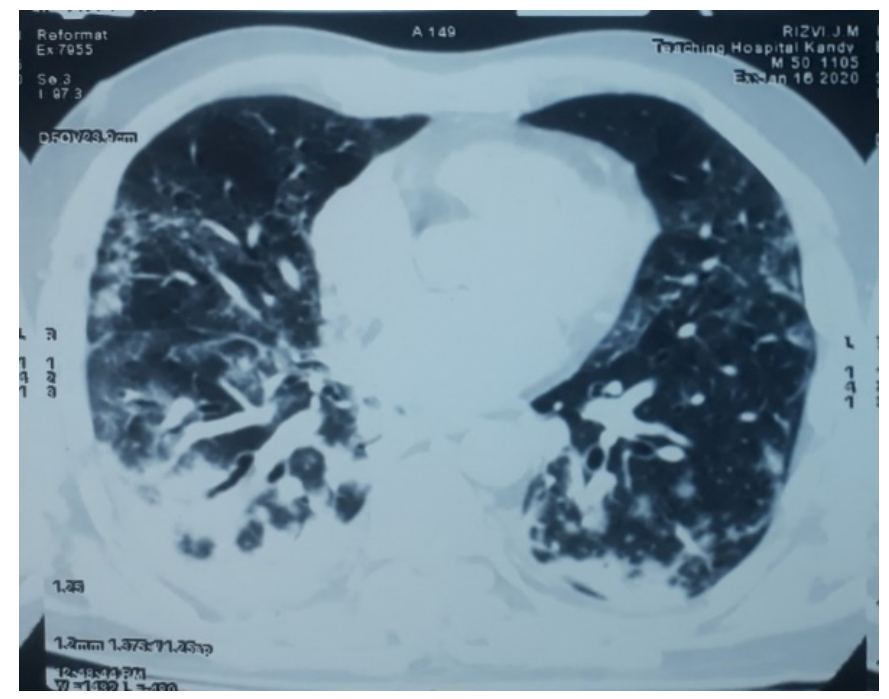

Figure 03: HRCT chest showing areas of consolidations, patchy ground glass infiltrations with some nodules

The clinical picture and HRCT findings led to the diagnosis of BOOP following influenza A. Hence, intravenous steroid therapy was administered with methyl prednisolone $1 \mathrm{~g}$ daily for 3 days followed by oral prednisolone $1 \mathrm{mg} / \mathrm{kg} /$ day. However, the patient deteriorated further both clinically and radiologically. As there was poor response to steroids, next option was explored and intravenous Cyclophosphamide was commenced with a dose of $500 \mathrm{mg}$ as an infusion. A remarkable improvement was observed in the clinical status of the patient after two pulses of Cyclophosphamide given two weeks apart. He was successfully weaned off from the mechanical ventilation. The 
repeat chest radiography also showed significant improvement. (Figure 4). The patient was given another 4 doses of cyclophosphamide monthly.

During the follow up, lung function assessment (table 01), 6min working test (6MWT) and HRCT chest (Figure 05 ) were carried out and all showed remarkable improvement.

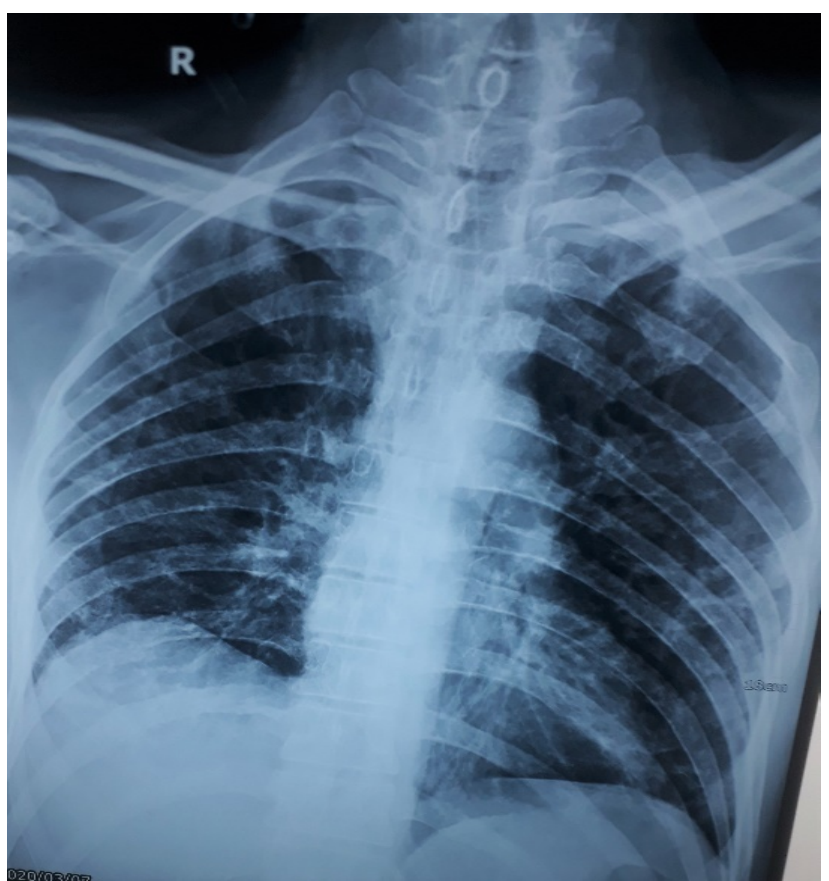

Figure 04: Chest radiography showing resolution of previousely noted consolidations

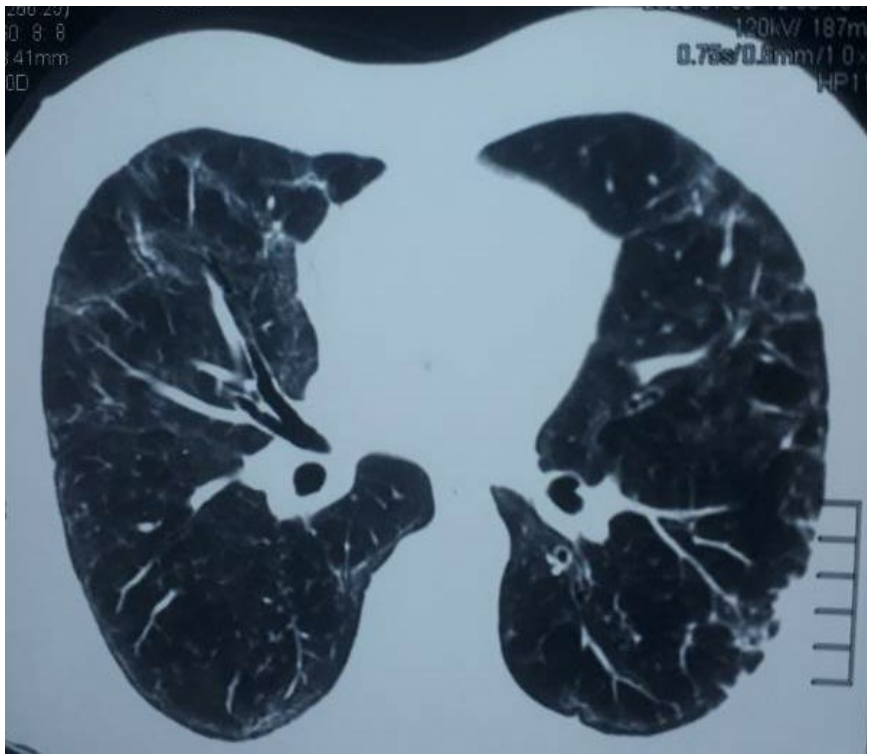

Figure 05: Previously noted consolidations, nodules and ground glass appearance were resolved

Table 01

\begin{tabular}{|c|c|c|}
\hline Lung function test & At the initial stage of treatment & During the follow up after 4 months \\
\hline FVC & $1.7 \mathrm{~L}$ of predicted & $2.3 \mathrm{~L}$ of predicted \\
\hline FEV1 & $1.4 \mathrm{~L}$ of predicted & $1.8 \mathrm{~L}$ of predicted \\
\hline FEV1 / FVC & $82 \%$ of predicted & $78 \%$ of predicted \\
\hline
\end{tabular}




\section{DISCUSSION}

Organizing pneumonia is characterized by the presence of granulation tissue in the bronchiolar lumen, alveolar duct and some alveoli, associated with a variable degree of interstitial and airspace infiltration by fibroblasts and myofibroblasts [6]. It may occur without any detectable cause or may be associated with various etiological conditions. Among them infection, medications, connective tissue disorders are common [1], [2]. When an underlying cause is not present it is subcategorized as idiopathic organizing pneumonia (Cryptogenic Organizing pneumonia, COP), whereas it is categorized as secondary BOOP or secondary organizing pneumonia (OP) when an underlying cause is identified [7]. Symptoms of BOOP develop gradually over few weeks to months. Common symptoms are productive cough, fever, malaise, fatigue, weight loss, and eventually progressive shortness of breath. However, patients may have other symptoms depending on the underlying etiology. The clinical examination will reveal diffuse crepitations of lungs in majority of patients.

A variety of plain radiographic findings are found with BOOP, although no radiographic features are diagnostic of the disease. A thorough knowledge regarding radiological menifestations of OP is crucial for making the correct diagnosis especially in situation where lung biopsy is challenging due to patient's factors [8]. The typical HRCT features include peripheral parenchymal consolidations with air bronchogram with or without surrounding ground glass [8], [9]. However other radiological features include basal airspace consolidation, centrilobular nodules, Pleural effusions, rarely cavitating lung masses and mild mediastinal lymphadenopathy [10].

B00P following respiratory infection occur with viral pneumonias such as Influenza A, and B, adenovirus, cytomegalovirus, and bacteria like legionella, chlamydia, and also fungal infection like Cryptococcus neoformans, [11].

Only few case reports have been published up to date regarding Organizing Pneumonia associated with Influenza A infection [12]. Therefore, BOOP should be considered as a rare but important differential diagnosis when a patient with severe influenza pneumonia fail to show adequate response to antiviral therapy. Majority of patients following BOOP show good response to corticosteroid therapy [3], [4]. However, in a minority of cases, disease may rapidly progress despite steroid treatment, which will be associated with poor prognosis.

As this patient showed inadequate response to the standard treatment of BOOP with steroids, alternative treatment modalities were sought. Although the evidence in the literature was not compelling, the patient was started on intravenous cyclophosphamide pulse therapy which led to the dramatic response observed in the patient. Therefore, this case highlights the value of cyclophosphamide therapy as an alternative treatment modality in steroid resistant BOOP.

\section{CONCLUSION}

In the clinical setting of managing steroid resistant cases of BOOP it is worthwhile to explore other treatment options, even with limited evidence to support its use. However, this should be done with critical evaluation of possible treatment related complications.

Management of steroid resistant BOOP is a challenging situation. It is worthwhile to explore novel treatment modalities such as cyclophosphamide in such situations, although the existing evidence for its use is limited. However, critical evaluation of possible treatment related complications is necessary for the optimum outcome.

\section{CONSENT}

Informed written consent was obtained from the patient for publication of this case and accompanying images.

\section{AUTHORS' CONTRIBUTIONS}

IN, AL and LB drafted the manuscript. DM supervised the research and manuscript, BI involved in management. 


\section{AUTHOR'S INFORMATION}

IN.AL and LB (MD) are Senior Registrars in Respiratory Medicine. DM (MD, FRCP) is a Senior Consultant Respiratory Physician. BI (MD) is an Intensive care Physician.

\section{SOURCES OF FUNDING}

This research received no specific grant from any funding agency in the public, commercial, or not-for-profit sectors.

\section{CONFLICT OF INTEREST}

The author have declared that no competing interests exist.

\section{ACKNOWLEDGMENT}

None.

\section{REFERENCES}

[1] Petitpierre N, Beigelman C, Letovanec I, Lazor R. Pneumopathie organisée cryptogénique [Cryptogenic organizing pneumonia]. Rev Mal Respir. 2016 Oct;33(8):703-717. French. doi: 10.1016/j.rmr.2015.08.004. Epub 2016 Feb 5. PMID: 26857200.

[2] Chandra D, Maini R, Hershberger DM. Cryptogenic Organizing Pneumonia. 2020 Sep 18. In: StatPearls [Internet]. Treasure Island (FL): StatPearls Publishing; 2020 Jan-. PMID: 29939651.

[3] Ruth-Sahd LA, White KA. Bronchiolitis obliterans organizing pneumonia. Dimens Crit Care Nurs. 2009 SepOct;28(5):204-8. doi: 10.1097/DCC.0b013e3181ac49ce. PMID: 19700963.

[4] Nuñez-Conde A, Marquez-Algaba E, Falcó V, Almirante B, Burgos J. Organizing pneumonia secondary to influenza infection: Two case reports and a literature review. Enferm Infecc Microbiol Clin. 2020 Mar;38(3):123-126. English, Spanish. doi: 10.1016/j.eimc.2019.04.006. Epub 2019 May 22. PMID: 31126691.

[5] Schlesinger C, Koss MN. The organizing pneumonias: a critical review of current concepts and treatment. Treat Respir Med. 2006;5(3):193-206. doi: 10.2165/00151829-200605030-00005. PMID: 16696589.

[6] Huo Z, Feng R, Tian X, Zhang H, Huo L, Liu H. Clinicopathological findings of focal organizing pneumonia: a retrospective study of 37 cases. Int J Clin Exp Pathol. 2015 Jan 1;8(1):511-6. PMID: 25755741; PMCID: PMC4348847.

[7] Drakopanagiotakis F, Polychronopoulos V, Judson MA. Organizing pneumonia. Am J Med Sci. 2008 Jan;335(1):34-9. doi: 10.1097/MAJ.0b013e31815d829d. PMID: 18195581.

[8] Zare Mehrjardi M, Kahkouee S, Pourabdollah M. Radio-pathological correlation of organizing pneumonia (OP): a pictorial review. Br J Radiol. 2017 Mar;90(1071):20160723. doi: 10.1259/bjr.20160723. Epub 2017 Feb 17. PMID: 28106480; PMCID: PMC5601538.

[9] Polverosi R, Maffesanti M, Dalpiaz G. Organizing pneumonia: typical and atypical HRCT patterns. Radiol Med. 2006 Mar;111(2):202-12. English, Italian. doi: 10.1007/s11547-006-0021-8. PMID: 16671378.

[10] Al-Ghanem S, Al-Jahdali H, Bamefleh H, Khan AN. Bronchiolitis obliterans organizing pneumonia: pathogenesis, clinical features, imaging and therapy review. Ann Thorac Med. 2008;3(2):67-75. doi:10.4103/1817-1737.39641

[11] Llibre JM, Urban A, Garcia E, Carrasco MA, Murcia C. Bronchiolitis obliterans organizing pneumonia associated with acute Mycoplasma pneumoniae infection. Clin Infect Dis. 1997 Dec;25(6):1340-2. doi: 10.1086/516124. PMID: 9431373.

[12] Liu H, Li J, Chen M, Su J. Glucocorticoid treatment of suspected organizing pneumonia after H7N9 infection: A case report. Medicine (Baltimore). 2019 Aug;98(34): e16839. doi: 10.1097/MD.0000000000016839. PMID: 31441857; PMCID: PMC6716695. 